\title{
Real-time PCR detection of the $m g 219$ gene of unknown function of Mycoplasma genitalium in men with and without non-gonococcal urethritis and their female partners in England
}

\author{
Correspondence \\ Victoria J. Chalker \\ vicki.chalker@hpa.org.uk
}

Received 3 February 2009

Accepted 23 March 2009

\author{
Victoria J. Chalker, ${ }^{1}$ Karen Jordan, ${ }^{2} \dagger$ Tahir Ali ${ }^{1}$ and Cathy Ison ${ }^{1}$ \\ ${ }^{1}$ Sexually Transmitted Bacteria Reference Laboratory, Health Protection Agency Centre for \\ Infections, 61 Colindale Avenue, London NW9 5EQ, UK \\ ${ }^{2}$ Microbiology Laboratory, Northampton General Hospital Trust, Billing Road, Northampton NN1 \\ 5BD, UK
}

\begin{abstract}
Real-time PCR was employed to detect a region of the Mycoplasma genitalium mg219 gene, a gene of unknown function, in clinical samples. Amplification of DNA and signal production from 15 other species of human mycoplasmas and 14 other bacteria and viruses did not occur. Using a panel of 208 genital and rectal samples, the sensitivity when compared to the modified mgpa gene (encoding the major surface protein $\mathrm{MgPa}$ ) real-time PCR assay was found to be $100 \%$ and the specificity of the assay $99.5 \%$ with a positive predictive value of $80 \%$ and a negative predictive value of $100 \%$. The $m g 219$ gene was found to be in all strains of $M$. genitalium and was highly conserved. M. genitalium was detected in $3.9 \%(11 / 280,95 \% \mathrm{Cl} 2.1-6.9)$ of all male specimens, in $7.7 \%(10 / 130,95 \% \mathrm{Cl} 4.1-13.7)$ of patients with non-gonococcal urethritis (NGU) and in $0.7 \%(1 / 150,95 \% \mathrm{Cl}<0.01-4.1)$ of patients without urethritis. The presence of M. genitalium was significantly associated with NGU $(P \leqslant 0.01 ; 95 \% \mathrm{Cl} 0.88-0.98)$ and nonchlamydial-non-gonococcal urethritis ( $P=0.0005 ; 95 \% \mathrm{Cl} 0.84-0.97)$.
\end{abstract}

\section{INTRODUCTION}

Mycoplasma genitalium is a sexually transmitted bacterium that is primarily found in the human urogenital tract. It has also been detected in respiratory (Baseman et al., 1988), rectal (Taylor-Robinson et al., 2003) and synovial (Tully et al., 1995) specimens. Serological detection of M. genitalium is problematic due to cross-reactions with Mycoplasma pneumoniae antibodies (Clausen et al., 2001; Lind et al., 1984). Isolation via cell culture is slow and laborious and real-time PCR is currently used in the diagnosis of infected patients (Jensen, 2006). Originally isolated from men with urethritis (Tully et al., 1981), M. genitalium has been convincingly linked to non-gonococcal urethritis (NGU) and nonchlamydial-non-gonococcal urethritis (NCNGU) (Jensen, 2006). However, the full extent of $M$. genitalium infection, epidemiology, and role in cervicitis, pelvic inflammatory disease, infertility and other infections requires investigation

tPresent address: bioMérieux UK, Grafton Way, Basingstoke RG22 $6 \mathrm{HY}, \mathrm{UK}$.

Abbreviations: $C_{p}$, crossing point threshold; IPC, internal processing control; NCNGU, non-chlamydial-non-gonococcal urethritis; NGU, nongonococcal urethritis.

A sequence alignment of the $m g 219$ gene is available with the online version of this paper.
(Jensen, 2006). M. genitalium is sexually transmitted and a high prevalence has been found (58\%) in individuals with infected sexual partners (Keane et al., 2000). Sequence-based typing has identified identical isolate sequence types from sexual partners, cementing evidence for sexual transmission (Hjorth et al., 2006; Ma et al., 2008).

Several real-time PCR assays have been described for the molecular detection of $M$. genitalium, including those targeting mgpa, the 16S rRNA gene and p115 (for review see Jensen, 2006). The mgpa gene real-time assay has been shown to be of increased sensitivity to the $16 \mathrm{~S}$ rRNA method (Edberg et al., 2008). We sought to identify a new method for confirmation of PCR results with equal sensitivity to that of the mgpa gene assay. The $m g 219$ gene assay was developed and used to detect the presence of $M$. genitalium in parallel with the mgpa gene real-time PCR assay in 280 male genitourinary medicine clinic attendees and 23 female partners as part of a case-control doubleblinded study in patients with and without urethritis of known chlamydia and gonococcal infection status.

\section{METHODS}

Reference and validation material. The following reference strains, clinical isolates, specimens and genomic DNA were obtained from the 
National Collection of type Cultures (NCTC), Colindale, London, the American Type Culture Collection (ATCC), Virginia, USA, and the authors' laboratory: Acholeplasma laidlawii NCTC $10116^{\mathrm{T}}$, Mycoplasma amphoriforme NCTC $11740^{\mathrm{T}}$, Mycoplasma buccale NCTC $10136^{\mathrm{T}}$, Mycoplasma faucium NCTC $10174^{\mathrm{T}}$, Mycoplasma fermentans NCTC $10117^{\mathrm{T}}$, Mycoplasma genitalium NCTC $10195^{\mathrm{T}}$, Mycoplasma hominis NCTC $10111^{\mathrm{T}}$, Mycoplasma lipophilum NCTC $10173^{\mathrm{T}}$, Mycoplasma orale NCTC $10112^{\mathrm{T}}$, Mycoplasma penetrans ATCC $55252^{\mathrm{T}}$, Mycoplasma pirum NCTC $11702^{\mathrm{T}}$, Mycoplasma pneumoniae NCTC $10119^{\mathrm{T}}$, Mycoplasma salivarium NCTC $10113^{\mathrm{T}}$, Mycoplasma spermatophilum NCTC $11720^{\mathrm{T}}$, Ureaplasma parvum ATCC 33697 and Ureaplasma urealyticum NCTC $10177^{\mathrm{T}}$ (mollicute species); Lactobacillus vaginalis NCTC $12197^{\mathrm{T}}$; Prevotella bivia NCTC $11156^{\mathrm{T}}$; Mobiluncus curtisii NCTC $11656^{\mathrm{T}}$; Mobiluncus mulieris NCTC $11658^{\mathrm{T}}$; Streptococcus pyogenes NCTC 12067; Streptococcus agalactiae NCTC 12906; Escherichia coli NCTC 9001 ${ }^{\mathrm{T}}$; Staphylococcus aureus NCTC $8532^{\mathrm{T}}$; clinical isolate Neisseria gonorrhoeae H060160180; Chlamydia trachomatis L2, cell culture DNA; Treponema pallidum H05510345; clinical samples positive for Treponema pallidum; Haemophilus ducreyi; and herpes simplex virus (HSV-1).

Extraction of DNA from bacterial cultures. Cultures of mollicute species and other bacteria $(5 \mathrm{ml})$ were concentrated by centrifugation at $8000 \mathrm{~g}$ for $15 \mathrm{~min}$, resuspended in $180 \mu \mathrm{l}$ nuclease-free water and extracted using the Roche MagNAPure robot and DNA Isolation kit III (Roche Diagnostics) according to the manufacturer's instructions. DNA concentration was adjusted to approximately $20 \mathrm{pg}^{-1} \mathrm{l}^{-1}$ for use in the real-time PCR assay. DNA from culture isolates of $M$. genitalium (M30 10-4, M30 early 10-2, TW10-5G 10-4, TW10-6 G104, R-32G 10-3, TW48-5G 10-4, M2300 10-4, M2321 10-3, M2341 103, G37 10-4, M2288 10-3, UTMB-10G 10-4) was kindly donated by Jørgen Jensen (Statens Serum Institut, Copenhagen, Denmark).

Real-time PCR detection of $\boldsymbol{M}$. genitalium. Real-time PCR was performed using a Rotor-Gene 6000 (Corbett Life Science) and all primers and probes are listed in Table 1.

mgpa gene assay (alteration of primers). Real-time PCR detection of the mgpa gene based upon the method by Jensen et al. (2004) was adapted for use on a Rotor-Gene with a modification to the forward primer to reflect base changes between $M$. genitalium strains. The method includes amplification of a cloned internal processing control (IPC) that contains the same primer regions as the target with differing probe target and enables detection of samples inhibitory specifically to this PCR. Reaction volumes $(20 \mu \mathrm{l}$ in total) were used containing 1.25 U AmpliTaq Gold DNA polymerase
(Applied Biosystems), $0.5 \mu \mathrm{M}$ primers ( $\mathrm{MgPa} 355 \mathrm{~F}$ modified primer and $\mathrm{MgPa} 432 \mathrm{R}), 0.2 \mu \mathrm{M} \mathrm{MgPa} 380$ probe and $0.05 \mu \mathrm{M}$ IPCR probe, $0.1 \mathrm{ng}$ IPC DNA, $5 \mu \mathrm{M} \mathrm{MgCl}, 0.625 \mathrm{mM}$ dNTPs with dUTP (Applied Biosystems), $0.2 \mu \mathrm{l}$ AmpErase Uracil $N$-glycosylase (Applied Biosystems) and $5 \mu \mathrm{l}$ sample or positive/negative control. Uracil-DNA glycosylase was added to each reaction to eliminate carry-over contamination (Longo et al., 1990). Tubes were sealed and placed into the Rotor-Gene and the following cycling conditions were applied: initial denaturation at $95{ }^{\circ} \mathrm{C}$ for $5 \mathrm{~min}$ (transition rate $20{ }^{\circ} \mathrm{C}$ $\mathrm{s}^{-1}$; acquisition mode none); 45 quantification cycles of $95{ }^{\circ} \mathrm{C}$ for $15 \mathrm{~s}$ (transition rate $20^{\circ} \mathrm{C} \mathrm{s}^{-1}$; acquisition mode none) and $60{ }^{\circ} \mathrm{C}$ for $60 \mathrm{~s}$ (transition rate $20{ }^{\circ} \mathrm{C} \mathrm{s}^{-1}$; acquisition mode single). Data were analysed using Rotor-Gene software and copy number was estimated from crossing point threshold $\left(C_{\mathrm{p}}\right)$ relative to a positive control curve consisting of $5 \mathrm{ng}, 0.5 \mathrm{ng}, 0.05 \mathrm{ng}$ and $0.005 \mathrm{ng}$ per $5 \mu \mathrm{l} \mathrm{M}$. genitalium DNA. Samples that did not give a positive result and in which the IPC did not amplify were recorded as inhibitory and were repeated undiluted and diluted $1 / 10$ in nuclease-free water (Sigma).

mg219 gene assay. The $m g 219$ gene was identified as being specific to M. genitalium and absent from all other completed mycoplasma genomes (using ORFanage; Siew et al., 2004) and from other bacterial sequences within GenBank. A real-time PCR was developed targeting a 251 bp fragment of the $m g 219$ gene of M. genitalium strain G37 NCTC $10195^{\mathrm{T}}$ (2 $655586-265837$ in GenBank accession no. NC000908). The assay was run with identical reagents and conditions to those for the mgpa gene assay except for the primers and probes (Table 1), enabling running both assays together in the same tube or both assays on the same machine simultaneously and reducing testing time. To ensure that the $m g 219$ gene assay could be used as a confirmatory test, all samples in this study were performed in separate tubes to the mgpa gene assay.

mg219 gene assay validation. The sensitivity of the $m g 219$ gene assay was calculated in parallel by testing serial dilutions (in triplicate, $100 \mu \mathrm{g} \mathrm{ml}^{-1}-100 \mathrm{pg} \mathrm{ml}^{-1}$ ) of a DNA extract of M. genitalium strain G37 NCTC $10195^{\mathrm{T}}$. This DNA panel was also tested using the modified mgpa gene assay. In addition, a panel of DNA extracts from cultured isolates of M. genitalium (listed above) was tested using the mg219 gene assay. A panel of 208 anonymized clinical samples submitted to the laboratory were tested using the $m g 219$ gene assay and $m g p a$ gene assay to ascertain the efficacy of the $m g 219$ gene assay with differing sample types and to determine inhibition using the mgpa gene assay. A total of 30 liquid-based cytology samples, 18 genital ulcer swabs (16 penile, 2 vulval), 1 penile swab, 13 urethral swabs, 22 rectal swabs, 38 vaginal swabs, 40 endocervical swabs and 46 urines were analysed in both assays.

Table 1. Primers and probes

\begin{tabular}{|ll|}
\hline Name & \multicolumn{1}{c|}{ Sequence $\left(\mathbf{5}^{\prime} \rightarrow \mathbf{3}^{\prime}\right)$} \\
\hline MgPa355F modified (Jensen et al., 2004) & GAG AA(A/G*) TAC CTT GAT GGT CAG CAA \\
MgPa432R (Jensen et al., 2004) & GTT AAT ATC ATA TAA AGC TCT ACC GTT GTT ATC \\
MgPa380 probe (Jensen et al., 2004) & FAM-ACT TTG CAA TCA GAA GGT-BHQ1 \\
IPCR probe $\dagger$ & ROX-TCC TTC GTG ATA TCG GAC GTT GGC TG-BHQ2 \\
Mg219F (forward primer) & CAT AGT TCA TTA TGC GCA CCA GTT ACT TG \\
Mg219R (reverse primer) & CTC TTT AAC AAC AGG GGT TGG GAT TAG \\
Mg219 probe & Cy5-GGT GTG GAT CGA GCG GC-BHQ3 \\
\hline
\end{tabular}

${ }^{\star} \mathrm{A} / \mathrm{G}$ wobble - due to $15.6 \%$ of isolates having $\mathrm{G}$ at this position (underlined bases are $\mathrm{A}, \mathrm{A}, \mathrm{A}$ and $\mathrm{G}$ in $4.4,4.4,2.2$ and $2.2 \%$ of isolates, respectively, modified in this study from Jensen et al., 2004).

$\dagger$ IPCR probe, internal processing control probe. The method includes amplification of a cloned internal processing control that contains the same primer regions as the target with differing probe target, enabling detection of samples inhibitory specifically to this PCR (Jensen et al., 2004). 
The specificity of the $m g 219$ gene assay was determined using a panel of DNAs from all human mollicute species, additional bacterial species, common genital bacteria and viruses and clinical samples of known viral and bacterial status as listed above. Clinical samples were heat-inactivated at $50{ }^{\circ} \mathrm{C}$ for $10 \mathrm{~min}$ and swabs were then agitated in $1 \mathrm{ml}$ PBS for $5 \mathrm{~min}$ prior to centrifugation. A total of $1.8 \mathrm{ml}$ urine was concentrated by centrifugation at $8000 \mathrm{~g}$ for $15 \mathrm{~min}$, resuspended in $200 \mu \mathrm{l}$ of nuclease-free water and extracted using the Roche MagNAPure robot using DNA isolation kit III (Roche Diagnostics) according to the manufacturer's instructions.

Clinical screening. Between 26 March 2007 and 8 June 2007, a total of 286 males and 25 females were recruited to the study from a local Sexual Health Department. Six male patients were diagnosed with $N$. gonorrhoeae and excluded from the study. Two female recruits were subsequently excluded as their male partner's sample was unavailable. No urine specimen was provided for one of the females tested thus only an endocervical swab was tested for this patient. This resulted in a total of 280 consenting male attendees, 130 case male recruits with NGU and 150 control male recruits without urethritis, and 23 female partners. Ethical approval was given by the local National Health Service organization. Patients were excluded from the study if they: (i) were under the age of 16 years, (ii) had taken antibiotics during the last month or (iii) had passed urine within $1 \mathrm{~h}$ of their appointment. Patients were screened for $N$. gonorrhoeae by culture, for $C$. trachomatis by PCR (BD ProbeTec ET Amplified DNA Assay; Becton Dickinson) and for urethritis (defined as the presence of $\geqslant$ five polymorphonuclear lymphocytes per high-power field). A first void urine specimen was provided by all test subjects and in addition an endocervical swab from women. The DNA was extracted from these specimens using a MagNA Pure LC instrument and MagNA Pure LC Total Nucleic Acid isolation kit (Roche) and tested for $M$. genitalium using both the $m g 219$ gene and mgpa gene assays.

mg219 gene sequencing and alignments. The entire $m g 219$ gene (2655 597-266043 in GenBank accession no. NC000908) and flanking regions were amplified from cultures and clinical isolates by gradient PCR using primers upstream and downstream of $m g 219$ [primer MG219-upstream mapped to position -76 to -54 (upstream of the $m g 219$ start codon) and primer MG219-downstream mapped to position 503-525 (downstream of the $m g 219$ stop codon)], with an annealing temperature of $57-68{ }^{\circ} \mathrm{C}$ and Roche High Fidelity Taq. The resulting amplified fragments were purified and both strands of the PCR products were sequenced using the oligonucleotides MG219upstream and MG219-downstream. Sequencing was performed using the Dye Terminator Cycle Sequencing (DTCS) Quick Start kit (Beckman Coulter) following the manufacturer's instructions and using the CEQ 8000 Genetic Analysis System, and the consensus sequence for each strain was determined using the BioNumerics version 4.5 software package (Applied Maths) and CLUSTAL W software (Chenna et al., 2003).

Statistical analysis. All statistical analysis (Fisher's exact test and confidence intervals) was performed with GraphPad Quickcalcs (http:// www.graphpad.com/quickcalcs/index.cfm) (GraphPad Software) or in Microsoft Excel. The probability of a type I error $(\alpha)$ of 0.05 was taken for all analyses and $95 \%$ confidence intervals are included where relevant.

\section{RESULTS AND DISCUSSION}

\section{mg219 gene assay sensitivity}

M. genitalium was consistently detected in all DNA replicates at a concentration of $100 \mu \mathrm{g} \mathrm{ml}^{-1}-100 \mathrm{pg}$ $\mathrm{ml}^{-1}$, corresponding to a lower detection limit of $0.5 \mathrm{pg}$ per reaction in the $m g 219$ gene assay. Replicates less than $10 \mathrm{pg} \mathrm{ml}^{-1}$ could not be consistently detected. The $m g 219$ gene assay detected 825 copies or more of the target sequence in the $5 \mu \mathrm{l}$ samples used in the assay corresponding to $0.5 \mathrm{pg}$ per reaction (of extracted concentrated DNA from M. genitalium strain G37 NCTC $10195^{\mathrm{T}}$ ). This was equal to the modified mgpa gene assay tested in parallel on the same DNA samples. All positive clinical male urine samples included in the study contained on average $9.91 \times 10^{5}$ (from $7.0 \times 10^{0}$ to $6.43 \times 10^{6}$ ) copies of the target sequence per $5 \mu \mathrm{l}$ concentrated extracted DNA. This corresponds to $7.79 \times 10^{1}-7.15 \times 10^{7}$ copies per ml patient urine. The $m g 219$ gene assay was found to have $100 \%$ sensitivity in comparison to the mgpa gene assay. Positive samples amplified on average 2.0 cycles earlier in the $m g 219$ gene assay $\left(C_{\mathrm{p}} 32.6 \pm 5.2\right)$ than in the mgpa gene assay $\left(C_{\mathrm{p}}\right.$ $34.6 \pm 4.2)$.

\section{mg219 gene assay specificity}

The $m g 219$ assay was found to be highly specific in that DNA extracted from reference cultures (all human mollicute species and other common genital bacteria and viruses) did not give a positive signal in the assay. No significant homology of the target sequence was found with any other known genes with BLAST (Altschul et al., 1990). Of the clinical samples used to validate the assay, 4/208 (1.9\%, 95\% CI 0.6-5.0) were PCR-positive for $M$. genitalium in both the $m g 219$ gene and mgpa gene assays (0/46 urine, $2 / 22$ rectal swabs, $0 / 13$ urethral swabs, $0 / 18$ genital ulcer swabs, 0/30 liquid-based cytology samples, 0/ 38 vaginal swabs, $2 / 40$ endocervical swabs, $0 / 1$ penile swab). One rectal swab sample was found to be positive only in the $m g 219$ gene assay and insufficient sample prevented further investigation. These results could represent either a false-positive reaction, pipetting error or a genuine positive reaction that was only identified by the $m g 219$ gene assay. The study included a low number of positive samples; nonetheless, the $m g 219$ gene assay was found to have $99.5 \%$ specificity, a positive predictive value of $80 \%$ and a negative predictive value of $100 \%$ in comparison to the mgpa gene assay.

\section{mg219 gene sequence data}

The $m g 219$ gene was found to be both present in all DNA of cultured isolates examined and highly conserved. Of the DNA of cultured strains, M30 10-2 and 10-4, TW10-5G, TW10-6G, R-32G, TW48-5G, M2300, M2321, UTMB 10G and G37 (resequenced in this study) were all $100 \%$ identical to the NCTC $10195^{\mathrm{T}}$ G37 control strain (the alignment is shown in Supplementary Fig. S1 in JMM Online). Interestingly, all the base differences were found within two urethral strains only: M2341 10-3 was $93.1 \%$ identical with 40/569 bases differing and M2288 10-3 was $93.2 \%$ identical with 39/569 bases differing. Of these, 30 bases consisted of an insertion in M2341 and M2288 with 
the sequence AAGCAACTAAACAAACCAAAACAAAGCCAA located between positions 504 and 505 in the control strain. Of the remaining 10 bases, all were identical in both strains (position $72 \mathrm{G}$ to $\mathrm{A}, 284 \mathrm{~T}$ to $\mathrm{C}, 346 \mathrm{~T}$ to $\mathrm{C}, 354 \mathrm{C}$ to $\mathrm{T}, 362 \mathrm{C}$ to $\mathrm{A}, 426 \mathrm{G}$ to $\mathrm{A}, 458 \mathrm{~T}$ to $\mathrm{C}, 463 \mathrm{G}$ to $\mathrm{A}, 485 \mathrm{C}$ to A) except for an $\mathrm{A}$ insertion at position $524-525$ in M2341 only.

\section{Clinical data}

Overall, M. genitalium was detected by the $m g 219$ gene assay and the mgpa gene assay in $3.9 \%(11 / 280,95 \%$ CI 2.1-6.9) of all male specimens, in $7.7 \%(10 / 130,95 \%$ CI 4.1-13.7) of patients with NGU and in $0.7 \%(1 / 15095 \%$ $\mathrm{CI}<0.01-4.1)$ of patients without urethritis. The presence of $M$. genitalium was significantly associated with NGU ( $P$ $\leqslant 0.01,95 \% \mathrm{Cl} 0.88-0.98)$. M. genitalium was not detected in any of the 23 females or corresponding 23 male sexual partners. Patients with M. genitalium had a median age of 26.0 years. Inhibition was detected in $1 / 280(0.36 \%, 95 \%$ CI $<0.01-2.2)$ male urine specimens, $4 / 23$ female urine specimens and $4 / 23$ endocervical swabs $(17.4 \%, 95 \%$ CI 6.4-3.7.7), of which one female had inhibition in both samples. Repeat testing of dilutions of these samples resulted in removal of inhibition. Concordant results were found for all 11 samples positive in both the $m g p a$ gene and $m g 219$ gene assays. A further five males were positive in the mgpa gene assay only and on initial analysis and all had crossing points of 40 cycles or more. Repeat testing of these equivocal specimens was negative in the mgpa gene assay and the initial positive mgpa gene result was unrepeatable on further testing.

C. trachomatis infection was detected in 54/280 (19.3\%, 95\% CI 15.1-24.3) male recruits, considerably higher than for M. genitalium. This equates to a prevalence of $33.8 \%$ (44/130, $95 \%$ CI 26.3-42.4) in males with NGU compared to a prevalence of $6.7 \%(10 / 150,95 \%$ CI $3.5-11.9)$ in the control group $(P \leqslant 0.001,95 \% \mathrm{Cl} 0.6-0.8)$. The median age of patients positive for $C$. trachomatis was 22.5 years. Dual infection with both M. genitalium and C. trachomatis was detected in $2 / 280(0.7 \%, 95 \%$ CI $0.2-2.7)$ male patients. A total of 86 males had NCNGU. The prevalence level of $M$. genitalium in patients within this group was $10.5 \%$ (9/86, $95 \%$ CI 5.4-18.9; $P=0.0005)$.

C. trachomatis was detected in $26.1 \%(6 / 23,95 \%$ CI $12.3-$ 46.8) of women and in their corresponding male partner (26.1\%, 6/23, $95 \%$ CI 12.3-46.8). All C. trachomatisnegative females had $C$. trachomatis-negative male partners and C. trachomatis was detected in the partners of all $C$. trachomatis-infected males with partners in the study (100\%, 6/6, $95 \%$ CI 55.7-100).

The $m g 219$ gene assay showed excellent specificity and sensitivity and had an equal lower detection level to that of the modified $m g p a$ gene assay. The $m g 219$ gene is expressed as part of a polycistronic message from the $m g 218$ operon. This operon encodes phosphorylated proteins involved in cytadherence, gliding and terminal organelle curving and motile response (Burgos et al., 2007; Dhandayuthapani et al., 2002; Musatovova et al., 2003; Pich et al., 2008; Su et al., 2007). Using both NetPhos (Blom et al., 1999) and Phosida (Gnad et al., 2007), several potential phosphorylation sites are predicted in the Mg219 conserved hypothetical protein and it is likely that $\mathrm{Mg} 219$ is also phosphorylated. It could be involved in cytadherence and gliding, similar to the other proteins encoded by the $m g 218$ operon, and may function in response to environmental signals. The $m g 219$ gene is unique to and highly conserved in $M$. genitalium. $M$. genitalium was isolated most frequently from rectal swabs $(9.1 \%)$ and endocervical swabs $(5 \%)$ in this study and previous studies have isolated M. genitalium from the rectum of men (Taylor-Robinson et al., 1985, 2003). A higher prevalence in men suffering from urethritis has been repeatedly demonstrated (Björnelius et al., 2000; Deguchi et al., 2002; Horner et al., 1993; Jensen, 2006; Maeda et al., 2001). The significant association of $M$. genitalium with NGU $(7.7 \%)$ and NCNGU (10.5\%) seen in this study is in line with previous reports (Jensen, 2006; Moi et al., 2009). Few studies on the prevalence of $M$. genitalium in England have been undertaken, and M. genitalium was detected in $0.7 \%$ male patients without urethritis in this study. A larger study of female patients in England is needed to establish prevalence in this group. Additional data are required to determine whether widespread screening of asymptomatic patients is beneficial for epidemiological analysis; however, symptomatic NCNGU patients can now be and should be screened for $M$. genitalium when clinically relevant. No data are available regarding the prevalence of M. genitalium in the population of England in relation to differing areas and differing patient demographics, typing, antibiotic resistance and optimal treatment.

\section{Conclusion}

The mg219 gene assay for detecting M. genitalium in clinical samples is reproducible, highly specific and sensitive and is applicable to a wide range of specimen types. The $m g 219$ gene is highly conserved and present in all strains tested. Dual infections with $C$. trachomatis were found in $0.7 \%$ samples tested and overall $3.9 \%$ samples were PCR-positive for M. genitalium. M. genitalium was found in $0.7 \%$ asymptomatic males in this study and was associated with both NGU (7.7\%) and NCNGU (10.9\%).

\section{ACKNOWLEDGEMENTS}

The authors would like to thank Jørgen Jensen (Denmark) for providing DNA of $M$. genitalium strains and InterAct Proof of Concept funds from the Department of Trade and Industry for funding to V.J.C. for T.A., Northampton General Hospital for funding K. J. and Northampton GU Clinic for recruiting volunteers. Note, patent applied for, numbers PCT/GB2007/001913 and WO2007/138271. 


\section{REFERENCES}

Altschul, S. F., Gish, W., Miller, W., Myers, E. W. \& Lipman, D. J. (1990). Basic local alignment search tool. J Mol Biol 215, 403-410.

Baseman, J. B., Dallo, S. F., Tully, J. G. \& Rose, D. L. (1988). Isolation and characterization of Mycoplasma genitalium strains from the human respiratory tract. J Clin Microbiol 26, 2266-2269.

Björnelius, E., Lidbrink, P. \& Jensen, J. S. (2000). Mycoplasma genitalium in non-gonococcal urethritis: a study in Swedish male STD patients. Int J STD AIDS 11, 292-296.

Blom, N., Gammeltoft, S. \& Brunak, S. (1999). Sequence and structure-based prediction of eukaryotic protein phosphorylation sites. J Mol Biol 294, 1351-1362.

Burgos, R., Pich, O. Q., Querol, E. \& Piñol, J. (2007). Functional analysis of the Mycoplasma genitalium MG312 protein reveals a specific requirement of the MG312 N-terminal domain for gliding motility. J Bacteriol 189, 7014-7023.

Chenna, R., Sugawara, H., Koike, T., Lopez, R., Gibson, T. J., Higgins, D. G. \& Thompson, J. D. (2003). Multiple sequence alignment with the CLUSTAL series of programs. Nucleic Acids Res 31, 3497-3500.

Clausen, H. F., Fedder, J., Drasbek, M., Nielsen, P. K., Toft, B. Ingerslev, H. J., Birkelund, S. \& Christiansen, G. (2001). Serological investigation of Mycoplasma genitalium in infertile women. Hum Reprod 16, 1866-1874.

Deguchi, T., Yoshida, T., Yokoi, S., Ito, M., Tamaki, M., Ishiko, H. \& Maeda, S.-I. (2002). Longitudinal quantitative detection by real-time PCR of Mycoplasma genitalium in first-pass urine of men with recurrent nongonococcal urethritis. J Clin Microbiol 40, 3854-3856.

Dhandayuthapani, S., Rasmussen, W. G. \& Baseman, J. B. (2002). Stability of cytadherence-related proteins P140/P110 in Mycoplasma genitalium requires MG218 and unidentified factors. Arch Med Res 33, $1-5$.

Edberg, A., Jurstrand, M., Johansson, E., Wikander, E., Höög, A., Ahlqvist, T., Falk, L., Jensen, J. S. \& Fredlund, H. (2008). A comparative study of three different PCR assays for detection of Mycoplasma genitalium in urogenital specimens from men and women. J Med Microbiol 57, 304-309.

Gnad, F., Ren, S., Cox, J., Olsen, J. V., Macek, B., Oroshi, M. \& Mann, M. (2007). PHOSIDA (phosphorylation site database): management, structural and evolutionary investigation, and prediction of phosphosites. Genome Biol 8, R250.

Hjorth, S. V., Björnelius, E., Lidbrink, P., Falk, L., Dohn, B., Berthelsen, L., Ma, L., Martin, D. H. \& Jensen, J. S. (2006). Sequence-based typing of Mycoplasma genitalium reveals sexual transmission. J Clin Microbiol 44, 2078-2083.

Horner, P. J., Gilroy, C. B., Thomas, B. J., Naidoo, R. O. M. \& TaylorRobinson, D. (1993). Association of Mycoplasma genitalium with acute non-gonococcal urethritis. Lancet 342, 582-585.

Jensen, J. S. (2006). Mycoplasma genitalium infections. Diagnosis, clinical aspects, and pathogenesis. Dan Med Bull 53, 1-27.

Jensen, J. S., Björnelius, E., Dohn, B. \& Lidbrink, P. (2004). Use of TaqMan $5^{\prime}$ nuclease real-time PCR for quantitative detection of
Mycoplasma genitalium DNA in males with and without urethritis who were attendees at a sexually transmitted disease clinic. J Clin Microbiol 42, 683-692.

Keane, F. E., Thomas, B. J., Gilroy, C. B., Renton, A. \& TaylorRobinson, D. (2000). The association of Chlamydia trachomatis and Mycoplasma genitalium with non-gonococcal urethritis: observations on heterosexual men and their female partners. Int J STD AIDS 11, 435-459.

Lind, K., Lindhardt, B. O., Schütten, H. J., Blom, J. \& Christiansen, C. (1984). Serological cross-reactions between Mycoplasma genitalium and Mycoplasma pneumoniae. J Clin Microbiol 20, 1036-1043.

Longo, M. C., Berninger, M. S. \& Hartley, J. L. (1990). Use of uracil DNA glycosylate to control carry-over in polymerase chain reaction. Gene 93, 125-128.

Ma, L., Taylor, S., Jensen, J. S., Myers, L., Lillis, R. \& Martin, D. H. (2008). Short tandem repeat sequences in the Mycoplasma genitalium genome and their use in a multilocus genotyping system. BMC Microbiol 8, 130.

Maeda, S. I., Tamaki, M., Kojima, K., Yoshida, T., Ishiko, H., Yasuda, M. \& Deguchi, T. (2001). Association of Mycoplasma genitalium persistence in the urethra with recurrence of nongonococcal urethritis. Sex Transm Dis 28, 472-476.

Moi, H., Reinton, N. \& Moghaddam, A. (2009). Mycoplasma genitalium is associated with symptomatic and asymptomatic non-gonococcal urethritis in men. Sex Transm Infect 85, 15-18.

Musatovova, O., Dhandayuthapani, S. \& Baseman, J. B. (2003). Transcriptional starts for cytadherence-related operons of Mycoplasma genitalium. FEMS Microbiol Lett 229, 73-81.

Pich, O. Q., Burgos, R., Ferrer-Navarro, M., Querol, E. \& Piñol, J. (2008). Role of Mycoplasma genitalium MG218 and MG317 cytoskeletal proteins in terminal organelle organization, gliding motility and cytadherence. Microbiology 154, 3188-3198.

Siew, N., Azaria, Y. \& Fischer, D. (2004). The ORFanage: an ORFan database. Nucleic Acids Res 32, D281-D283.

Su, H. C., Hutchison, C. A., III \& Giddings, M. C. (2007). Mapping phosphoproteins in Mycoplasma genitalium and Mycoplasma pneumoniae. BMC Microbiol 7, 63.

Taylor-Robinson, D., Furr, P. M. \& Hanna, N. F. (1985). Microbiological and serological study of non-gonococcal urethritis with special reference to Mycoplasma genitalium. Genitourin Med 61, 319-324.

Taylor-Robinson, D., Gilroy, C. B. \& Keane, F. E. (2003). Detection of several Mycoplasma species at various anatomical sites of homosexual men. Eur J Clin Microbiol Infect Dis 22, 291-293.

Tully, J. G., Taylor-Robinson, D., Cole, R. M. \& Rose, D. L. (1981). A newly discovered mycoplasma in the human urogenital tract. Lancet $\mathbf{1}$, 1288-1291.

Tully, J. G., Rose, D. L., Baseman, J. B., Dallo, S. F., Lazzell, A. L. \& Davis, C. P. (1995). Mycoplasma pneumoniae and Mycoplasma genitalium mixture in synovial fluid isolate. J Clin Microbiol 33, 1851-1855. 